\title{
THE IMPACT OF STAKEHOLDERS IN AGILE SOFTWARE DEVELOPMENT
}

\author{
Paul Dragos \\ Department of Management, Faculty of Economics and Administrative Affairs, \\ West University, Timisoara, Romania \\ paul.dragos90@e-uvt.ro
}

\begin{abstract}
The market for software development projects is dynamic and complex. The stakeholders involved in the software development process come from different organisational positions and therefore have varying interests and expectations from the product. Effective project management practices enable successful on-time delivery of high-quality product. It is essential to identify the stakeholder roles and responsibilities to effectively manage the development practices within the organisation. Elucidating the stakeholder roles will enable stakeholder management via effective communication and sustainable practices that reflect stakeholder interests. This study elucidates the roles and responsibilities of the stakeholders associated with Agile software development projects. The study identifies that for effective stakeholder management practices understanding of the stakeholder roles and interests is vital. Additionally, application of Agile software development methodology would result in successful development of high-quality software solutions.
\end{abstract}

Keywords: Agile; software development; stakeholders; management; roles

JEL classification: O32; M11; M15; C88; D24

\section{Research Background}

Current business environment is complex and evolving as per the market requirements. Owing to this dynamic nature, the providers are compelled to hasten the launch of their new and innovative products into the market. The primary objective of Agile Software Development (ASD) is to help deliver the product on-time and ensure customer satisfaction (Ferreira and Cohen, 2008). With the help of ASD, the product development process has shifted to a more incremental and empirical approach which allows for an easy and immediate change in product development direction (Raharjo and Purwandari, 2020). ASD methodologies such as Scrum, Kanban, and Extreme Programming offer the necessary processes for product development. Several studies indicate that Agile practices help with improving team productivity as well as their contextual understanding of the product. Studies have reported that $71 \%$ of the organizations adopt Agile practices for project management and software development (PMI, 2017; Padalkar and Gopinath, 2016; Raharjo and Purwandari, 2020). The most important factor for effective work in ASD is the stakeholder interaction. Proactive stakeholders are necessary for overall success of agile software development projects. This study discusses the stakeholders involved in software development projects and their role in project success. 


\section{Literature Review}

This chapter investigates the existing literature to examine the researches on software engineering, software development, agile software development, etc. Specifically, it traces the impact of stakeholders on agile software development. This section will explore the roles and responsibilities of the stakeholders involved in software development projects.

\subsection{Software Engineering}

Software engineering is a subject that has experienced much advancement in an attempt to continue up with new technological breakthroughs and current business needs by developing efficient methods to the end software package (Stol \& Fitzgerald, 2018). One of these milestones is the development of an agile software. The agile software development model was presented to surpass the limitations of the traditional development approaches. It was also proposed to reduce the cost of the project. It also offers the support to make any changes if and when required (Braude \& Bernstein, 2016).

\subsection{Software Development}

Software development is an evolving stream of science with extensive knowledge and research of the practices and theories involved (Raharjo \& Purwandari, 2020). The process of conceptualizing, defining, designing, programming, researching, evaluating, and problem fixing that goes into developing and managing applications, systems, or other software modules is known as software development. Being a specialist in certain tasks necessitates specific capabilities, information, and experience. Introducing innovative functionalities, assessing constraints, and addressing defects are all part of the software development process (Hoda, Salleh, \& Grund, 2018).

\subsection{Project Management}

The project management practices adopted to handle such projects also require similar adaptability (Hitt, et al 2001). The project manager is someone who supervises a team of experts, for whom the role is defined in length, who hires the team members, performs project management plans, and can market the venture to clients. The project management body of knowledge has defined the project manager as the one who is assigned with the task to lead the team with proper planning and coordination in a way to achieve the aims and goals of the organization effectively (PMBOK, 2018).

\subsection{Traditional Software Development}

A conventional software development module, commonly known as Waterfall, is marked by some significant qualities. These features include thorough research, proper planning, prior data collection, comprehensive communication, and an emphasis on efficient workflow. It has been observed that many significantly 
important principles of conventional project management have been included in the Waterfall. These characteristics include the arrangement of the important developmental processes in an orderly form, a concentrate on substantial preplanning, and a sequenced approach (Kusters, Rutten \& Trienekens, 2017).

One of the biggest critiques leveled against the waterfall technique is its inability to adapt to changes in the project circumstances. The aspect that the progressive waterfall model does not work effectively in a dynamic design was noticed early on, prompting Boehm to suggest an alternative spiral model. This strategy emphasized risk management and involvement of the client in the project development. Boehm and Ross formulated a people-oriented approach to software project management. It argued that the project would only be effective if the project coordinator was responsible for formulating a bid contract for clients, investors, staff members, and relevant stakeholders (Boehm \& Ross, 1989).

Waterfall modules are comparatively slow and time taking whereas the agile software technology is rapid and involves short and quick cycles. This feature attracts more and more stakeholders to invest in the projects related to software development. The agile software development offers more details and more involvement in the development process that makes the stakeholders clear about the process. They are also provided with the option to set their preferences at any stage of development.

\subsection{Agile Modeling for Software Development}

The agile modeling for software development practices requires active stakeholder participation to gain information and feedback on the product being developed and help decide the direction of the development process as well as its prioritization. Studies have reported that the level of understanding among the stakeholders directly impacts the project's success. Survey studies by the Standish group have reported that less than $50 \%$ of the software development projects are successfully delivered within the set time, budget, and scope. The outcome of any project is determined by the individuals associated with its development process. Along with poor management practices, poor stakeholder management could result in project failure. The complete software development project depends entirely on the stakeholder's vision and requirements. Therefore, the direction of the project and the process prioritization is solely driven by the stakeholders. PMI defines the stakeholder as a "group of individuals or organizations that are actively involved in the project and whose interests directly influence the project's success" (PMI, 2011). The importance of stakeholder management was illustrated by Freeman (2010) through the "Strategic Management: A Stakeholder Approach".

\subsection{Agile Software-People Oriented}

A significant feature of agile software development is that it focuses significant importance on human aspects in the project like friendliness, creativity, competence, and interaction. These characteristics become a top priority for the aspiring agile team. Skill development is essential so that each individual may 
produce more value with less time. The focus on human concerns lends a distinction to agile initiatives (Cockburn, 2001).

\subsection{Stakeholders}

According to Nothaft and Wiesche (2021), stakeholders are individuals or workgroups who often interact with the product owner, project leader, and project manager to offer assistance in the development of the project's items \& services. They have a strong influence on the overall project as they are the major contributors to the whole process. They may be customers, employees, investors, and suppliers, etc.

Stakeholders are the ones who determine the specifications for the products to be designed and can therefore effectively assess if they are satisfied with the output or not. And also whether their demands have been effectively fulfilled or not. Other stakeholders may not have defined requirements about the products, but they may have a revenue target for the corporation (Koch, 2005).

\subsection{Stakeholders in Agile Software Development}

In a given scenario, the response of any system is determined by the specifications marked at the start. The responses are determined by the demands and aims of different stakeholders. All the approaches involve one or more stakeholders at one or another level of the project management. These are involved in the project in separate phases. But on the other hand, agile practices in software development involve the engagement of stakeholders at all levels. They are actively concerned throughout the process and are consulted for their opinion. Agile software development revolves around the indulgence of all stakeholders to the possible extent so that any change can be assessed timely. These changes may include the changing demands of the stakeholders, innovative technological aspects, or other factors affecting the software development process (Cao, et al., 2009).

\subsection{Involvement of the Stakeholders in Agile Software Development}

Over the years, the changes in the business sector shifted the focus on incorporating the stakeholder needs and interests from a social perspective (Waddock \& Mcintosh, 2009). An increasing number of studies have reported the advantages of stakeholder engagement and the importance of cooperation for achieving a competitive edge on the global business platform (Sudevan et al, 2014). Stakeholder engagement targets, that also include the involvement of the different stakeholders in the decision-making process, improve the competency of the (Sudevan et al., 2014). The stakeholders should be engaged to collect the relevant information from them. The collected information should be compared to frame any strategy. The involvement of stakeholders is highly effective in planning and framework (Cheng \& Lui, 2008).

Effective communication between stakeholders associated with the project paves the path to sustainable practices that reflect the stakeholders' interest (Sudevan et 
al, 2014). Thus, with proper stakeholder management practices, the direction and progress of the project would improve significantly and result in success. In software development projects its success is based on product quality and meeting stakeholder expectations. The stakeholders in a software development project range from different corporate positions and thus have different interests in the project.

\subsection{Stakeholders' Job Satisfaction}

Development teams must satisfy the demands of multiple stakeholders in order to thrive and go ahead (Leffingwell, 2011). The review of the literature has suggested that there is a direct link is found between the standard of information and the job satisfaction of stakeholders. The work satisfaction of clients is also determined by a system's technological capabilities. The techno-stress and its influence on users' work satisfaction, commitment, and determination to the organization have been studied and evaluated. The most important findings described are as follows: stress issues lower work satisfaction, resulting in diminished organizational and individual dedication (Joshi \& Rai, 2000).

On the other hand, the stress-reduction factors have a reverse impact (Nathan et al., 2008). Wamba \& Bhattacharya (2015) has suggested that the factors that affect the job satisfaction of the stakeholders should be considered and dealt with accordingly. According to Neteller, et al., 2017, the success of any firm lies in job satisfaction. So the corporate should focus on this factor and try to improve this aspect.

Stakeholder satisfaction is important. They should be engaged in agility assessments. The studies have suggested that the involvement of stakeholders in the project development, obtaining their critical feedback, reassures stakeholders that their input is significant and acknowledged. Stakeholders are critical to the project's success. Their desires and requirements drive the product, and their input assists in advancing both the product and the process, concluding in a positive end.

\subsection{Impact of Stakeholders on Software Development}

The number of stakeholders involved in a specific project may vary depending on the nature of the project. The large projects may involve more stakeholders to assist the execution of the objectives. All the stakeholders involved vary in their views and opinions. They may have different aims and interests regarding the projects. They should be given detailed attention to enhance the effectiveness of the project. As their involvement in agile software development supports the development and execution of the project. All these interests and concerns should be merged into a single comprehensive framework to ensure the efficiency of the process (Khan, Khalid \& Haq, 2013).

The stakeholders are the ones who have an interest in some specific software development and they involve in the project with some aims. Their views should be respected and their interests should be safeguarded. Their contribution is very significant for the execution of the project (Sommorville \& Kotonya, 2000). While involving the stakeholders in the project, the relevant stakeholders should be 
approached to avoid any sort of incompetency in the task. They should be questioned about their goals, risk factors, investment interest prior to their engagement in the project (Lausean, 2002).

\subsection{Collaboration and Interaction with the Stakeholders}

Stakeholders are the driving force behind product development. They have certain demands and needs that the development team must meet. Their goals and requirements, on the other hand, are not always apparent; in fact, the Stakeholder might not always know precisely what they really want, and as a consequence, frequent meetings are usually required to obtain a clear understanding for both sides. The collaboration of stakeholders is an important part of project management. To enable successful cooperation and a higher possibility of project success, effective communication should be maintained (Buchan, MacDonell \& Shinde, 2017).

Stakeholders should be brought in as early as feasible in the process. Involvement in talks about requirements and narrative mapping will help them sound participated in the process and appreciated (Ram, Rodriguez \& Oivo, 2018). Establishing this approach in the initial stages helps Stakeholders realize that their participation in the project is valued and anticipated, establishing a precedent for their future involvement. Stakeholders should be employed early in the process as feasible to acquire knowledge of project worth and the utilization of the finished product.

The key to effective engagement is the proper communication and coordination with the stakeholders of the project. The major obstacles in coordinating an agile project have been maintaining interactions between different major stakeholders who were previously used to collaborating in a traditional approach and a lack of relevant technical expertise on the client's perspective, which may require substantial education programs. A comprehensive communication approach is required to overcome this barrier and prevent any loss in the project (Chen \& Lvova, 2011).

Stakeholders may find it challenging to comprehend how they will be benefited from a product, especially if they are not the final consumer. This inadequate knowledge might have an impact on Stakeholders' active participation. For that, the significance of the project should be explained to them to promote their participation in the project (Avikainen \& Leppänen, 2017).

Involving stakeholders in decision taking practices will encourage them. Despite the fact that the product manager makes the ultimate decision, Stakeholders play a significant role in the context. Product owners make judgments based on a variety of criteria and take decisions conveyed to them by stakeholders. It is consequently critical that both entities maintain consistent interaction.

\subsection{Identification of stakeholders for Agile Software Development}

The agile software development must involve multiple but relevant stakeholders to ensure the successful completion of the project. A study of the literature has revealed a significantly positive link between agility and stakeholder support 
(Juhole et al., 2014). Power has devised a model to investigate the appropriate stakeholders for the projects and their impact on output. The model suggests that effective communication and interaction with the stakeholders help the corporation in achieving its goals (Power, 2010).

Identifying people with relevant competence, taking time, and being consistent are all concerns for working with stakeholders, according to Hanssen and Fgri (2006). Matook and Maruping (2014) studied the importance of finance, social aspects, and systems capabilities in agile projects. The involvement of stakeholders in an agile environment in a comprehensive approach has been effective by Conboy and Morgan (2011).

A stakeholder management approach typically includes the identification of the appropriate stakeholders, planning a strategic management approach to engage the stakeholders, organizing the communication channels, and meeting their expectations and demands. Projects that employ an agile approach are aimed at people, iterations, and implementation of the aims (Adjeii \& Rwakatiwana, 2009). A distinct project purpose, effective stakeholder involvement throughout the initiative, the interaction of stakeholders, progressive output are the features associated with the agile approach in the development (Haas, 2007).

\subsection{Stakeholder Management}

According to Fitsilis (2008), stakeholder management involves management skills, human resource management strategies, and the quality management approach. The management skills involve managing and organizing the whole developmental procedure, human resource management expertise is concerned with the human aspects of the project while quality management ensures the frequent assessment and review of the project (Fitsilis, 2008).

The specifications and requirements of the stakeholders should be given prime importance in the project. As the agile software development success is backed by the strong interaction and communication between the stakeholders. The understanding and fulfillment of the interests and concerns of the stakeholders help in the advancement of the project (Chen \& Lvova, 2011.

\section{Research Methodology}

This section describes the research methodology that is used for the study. Content analysis of the articles was conducted to identify the myriad roles of stakeholders in Agile software development projects. The study aims to answer: What are the roles of stakeholders in Agile software development projects? The studies that explored the importance of stakeholders in Agile software development projects were chosen for content analysis. The publication date for the selected studies ranged from the year 2001 to 2020. The 19-year timeline chosen was appropriate for analysing the variables (Shaffril et al., 2018). The study only considered articles written in English language, publishedpeer-reviewed journals, between 2001 and 2020. All articles which did not fit the selection criteria were excluded. The studies associated with keywords such as "Agile", "Software Development", "Stakeholder", and "Stakeholder Roles" were selected. 


\section{Results}

Stakeholder in software development projects is directly associated with the product outcome. A stakeholder could be the direct or indirect product user, managers, in charge of operations, product sponsor, developer, or support staff. The stakeholder interests are therefore as diverse as the organisational background of the people involved. Thus, to achieve project success it is necessary to understand the stakeholder requirements to form a cohesive vision for project direction and priorities. If we consider arranging the stakeholders involved in an Agile Software development project in an onion diagram, the product makes up the core of the onion being the most crucial aspect of the project and the stakeholders in layers closest to farthest represent their roles in the product development process. The Users, Support staff and System administrators are primary stakeholders. While, the Technical and User management groups, sales and purchasing group, and the legal group are secondary stakeholders. The sponsors, client, suppliers, regulators, developers, public, and media are the tertiary stakeholders (Caprano, n.d.; Power, 2010). The most involved group of stakeholders are Project Sponsors, Product owner, Product Developers, Project Managers, and Product User. The project sponsors are the external stakeholders as they are mainly interested in the project success. Their role is to organise the financial help necessary for the project. To find out the alternatives for project cost overruns is also included in their tasks. The project owner is the primary stakeholder responsible for setting the goals and business strategy for the project. Additionally, the owner also plays an important role in clearing backlogs to help the team with project direction and prioritization. Developers among other stakeholders are involved in the actual software development process. The development team includes the software designers, product testers and team leaders. Their role is to successfully deliver the software on time and quality estimation of the product. The project managers handle the complete planning and organization so the project is completed within the estimated time, scope and requirements. In Agile software development, the project manager is an integral part of the development process and is responsible for communicating with the other stakeholders regarding the requirements, budget and deadlines of the project. The end user is the target audience for the product. If engaged in a proper manner, the end user can support the development process by testing the product and provide feedback for improvements to the final product (Buchan et al., 2017).

\section{Conclusion}

Development of high-quality software solutions requires identification and categorization of stakeholders' roles and responsibilities as they wield influence on the project process and its outcome. In an Agile software development project, the sponsor has a high influence on the project since they can withdraw the funding if the outcome is not to their liking. The technical and administrative staff on the other hand have minimal influence in terms of project outcome. However, they can significantly influence the project process which aid in achieving said outcome. Hence, for efficient project management, it is very essential to trace the relevant stakeholders and develop interaction with them. It would help in estimating the 
stakeholders' perception towards project decisions. Thus, making it easier to determine their interest and requirements from the product. Effective and cohesive communication among the stakeholders can set the project direction and help in proper prioritization of the product development processes. Application of Agile methodology enables a productive collaboration of stakeholders for development of specific high quality software solutions.

\section{References}

1.Abid, M.A., Din, Z.U., Khan, M.I. and Naeem, T., 2020. FACTORS AFFECTING REQUIREMENTS ENGINEERING IN AGILE SOFTWARE DEVELOPMENT: A SYSTEMATIC ANALYSIS.

2.Buchan, J., Bano, M., Zowghi, D., MacDonell, S. and Shinde, A., 2017, June. Alignment of stakeholder expectations about user involvement in agile software development. In Proceedings of the 21st International Conference on Evaluation and Assessment in Software Engineering (pp. 334-343).

3.Braude, E.J. and Bernstein, M.E., 2016. Software engineering: modern approaches. Waveland Press.

4.Caprano, C., Identifying and Structuring Challenges in Adopting Agile and Lean Practices in Large Organizations based on a Literature Analysis.

5.Cao, L., Ramesh, B. and Abdel-Hamid, T., 2010. Modeling dynamics in agile software development. ACM Transactions on Management Information Systems (TMIS), 1(1), pp.1-26.

6.Ciric, D., Lalic, B., Gracanin, D., Tasic, N., Delic, M. and Medic, N., 2019. Agile vs. Traditional approach in project management: Strategies, challenges and reasons to introduce agile. Procedia Manufacturing, 39, pp.1407-1414.

7.Conboy, K. and Morgan, L., 2011. Beyond the customer: Opening the agile systems development process. Information and Software Technology, 53(5), pp.535-542.

8.Cockburn, A. and Highsmith, J., 2001. Agile software development, the people factor. Computer, 34(11), pp.131-133.

9.Fitsilis, P., 2008. Comparing PMBOK and Agile Project Management software development processes. In Advances in Computer and Information Sciences and Engineering (pp. 378-383). Springer, Dordrecht.

10. Freeman, R.E., 2010. Strategic management: A stakeholder approach. Cambridge university press.

11. Hoda, R., Salleh, N. and Grundy, J., 2018. The rise and evolution of agile software development. IEEE software, 35(5), pp.58-63.

12. Huck-Fries, V., Nothaft, F. and Wiesche, M., 2021, January. Investigating the Role of Stakeholders in Agile Information Systems Development Projects: A Mixed Methods Approach. In Proceedings of the 54th Hawaii International Conference on System Sciences (p. 6806).

13. Chen, H. and Lvova, L., 2011. Stakeholder Management in Agile Public Projects Case Study of municipal project" Innoveta KC".

14. Khan, M.N.A., Khalid, M. and ul Haq, S., 2013. Review of requirements management issues in software development. International Journal of Modern Education and Computer Science, 5(1), p.21. 
15. Kulkarni, R.H., Padmanabham, P., Harshe, M., Baseer, K.K. and Patil, P., 2017. Investigating Agile Adaptation for Project Development. International Journal of Electrical \& Computer Engineering (2088-8708), 7(3).

16. Kusters, R.J., van de Leur, Y., Rutten, W.G. and Trienekens, J.J., 2017, April. When agile meets waterfall-investigating risks and problems on the interface between agile and traditional software development in a hybrid development organization. In International Conference on Enterprise Information Systems (Vol. 2, pp. 271-278). SCITEPRESS.

17. Koch, A.S., 2005. Agile software development: evaluating the methods for your organization. Artech house.

18. Leffingwell, D., 2010. Agile software requirements: lean requirements practices for teams, programs, and the enterprise. Addison-Wesley Professional.

19. Majanoja, A.M., Avikainen, P. and Leppänen, V., 2017, April. The impact of agile software development approach on software developers' responsibilities. In World Conference on Information Systems and Technologies (pp. 581-591).

20. Springer, Cham.Matook, S. and Maruping, L.M., 2014. A competency model for customer representatives in agile software development projects. MIS Quarterly Executive, 13(2).

21. Nguyen, T.S. and Mohamed, S., 2021. Mediation Effect of Stakeholder Management between Stakeholder Characteristics and Project Performance. Journal of Engineering, Project \& Production Management, 11(2).

22. Padalkar, M. and Gopinath, S., 2016. Six decades of project management research: Thematic trends and future opportunities. International Journal of Project Management, 34(7), pp.1305-1321.

23. Richardson, G.L. and Jackson, B.M., 2018. Project management theory and practice. Auerbach Publications.

24. Raharjo, T. and Purwandari, B., 2020, January. Agile project management challenges and mapping solutions: a systematic literature review. In Proceedings of the 3rd International Conference on Software Engineering and Information Management (pp. 123-129).

25. Ram, P., Rodriguez, P. and Oivo, M., 2018, November. Software process measurement and related challenges in agile software development: A multiple case study. In International Conference on Product-Focused Software Process Improvement (pp. 272-287).

26. Springer, Cham.Sudevan, S., Bhasi, M. and Pramod, K.V., 2014. Existing Software Stakeholder Practices an Overview. International Journal of Computer Applications, 102(3).

27. Shaffril, H.A.M., Krauss, S.E. and Samsuddin, S.F., 2018. A systematic review on Asian's farmers' adaptation practices towards climate change. Science of the Total Environment, 644, pp.683-695.

28. Stol, K.J. and Fitzgerald, B., 2018. The ABC of software engineering research. ACM Transactions on Software Engineering and Methodology (TOSEM), 27(3), pp.1-51.

29. Waddock, S. and Mclntosh, M., 2009. Beyond corporate responsibility: Implications for management development. Business and Society Review, 114(3), pp.295-325. 